\title{
生长碳纳米管用碳化物催化剂的浮动制备新方法
}

魏飞

清华大学化工系, 北京 100084

\section{Floating Carbide Solid Catalyst for Growing Carbon Nanotubes with Controlled Structure}

\section{Fei Wei}

Department of Chemical Engineering, Tsinghua University, Beijing 100084, P. R. China.

Email: wf-dce@mail.tsinghua.edu.cn.

Published online: April 9, 2020.

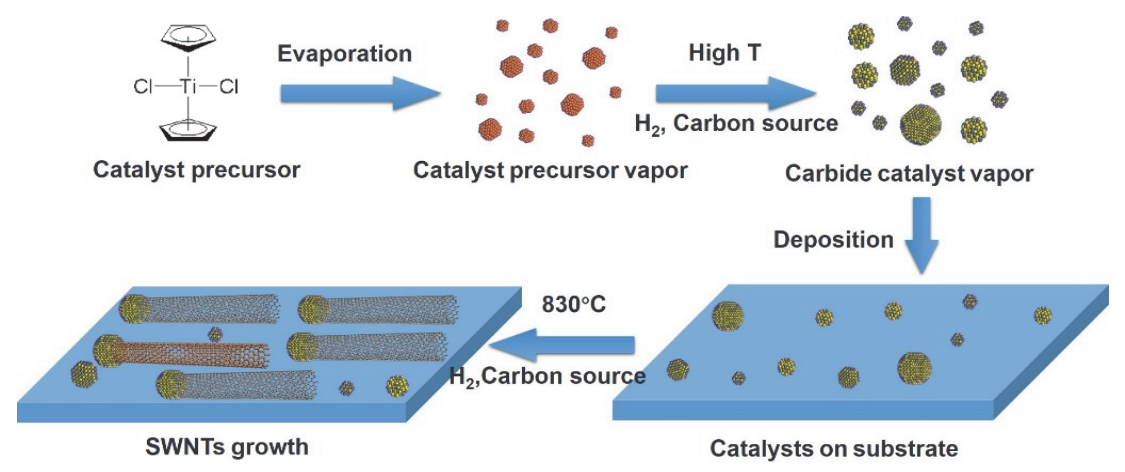

浮动法制备碳化物固体催化剂并生长结构可控的单壁碳纳米管的示意图。

催化剂的设计与制备是碳纳米管结构控制生 长中永恒的主题 ${ }^{1}$ 。近年来, 通过催化剂设计, 碳 纳米管的结构控制制备已取得了一系列重要进 展, 并对催化剂的作用机制有了更深入的认识。从 形态上讲, 固体催化剂比液态催化剂在在碳纳米 管生长温度下具有更加稳定的结构, 对碳纳米管 热力学成核表现出更加有效的选择性 ${ }^{2,3}$; 从生长 模式上, “气 - 固”(VS) 模式比经典的“气 - 液 固”(VLS)模式, 对碳纳米管生长动力学的调控更 为有利 ${ }^{4-6}$; 如何实现固体催化剂的放量制备是结 构可控碳纳米管放量制备的前提, 也是实现碳纳 米管从基础研究到商业应用的必经之路 7,8 。目前, 单壁碳纳米管生长使用的固体催化剂可以在基底 表面利用氧化物前驱体碳化形成 ${ }^{3}$, 也可以通过金 属间化合物还原得到 ${ }^{2}$, 但通过这些方式获得的固 体催化剂的数量有限, 很难大规模使用。因此, 发 展原位制备大量固体催化剂的新方法, 并进一步
实现手性单一的碳纳米管的宏量制备成为亟待解 决的重大问题。

北京大学张锦教授研究组最近提出的一种碳 化物固体催化剂的浮动制备方法(FSC)正是针对 性地解决了这一问题9。在该方法中, 研究者采用 了二氯二茂钛作为碳化物固体催化剂制备的前驱 体, 结合浮动的方法, 在化学气相沉积系统中直接 获得了碳化物催化剂并实现了碳纳米管的生长。经 过高分辨透射电镜分析, 研究者确认了碳化钛固 体催化剂四重对称的(200)晶面是碳纳米管成核 和生长的直接模板。对碳纳米管的手性分析显示 其手性以四重对称的 $(16,8),(12,8),(16,0),(20,0)$ 等碳纳米管为主, 进一步证实了他们之前提出的 碳纳米管对称性匹配成核理论 ${ }^{3}$ 。通过改变碳源种 类以及提高碳源供给量, 研究者最终在碳化钛固 体催化剂表面实现了纯度高达 $74 \%$ 的四重对称的 $(16,8)$ 碳纳米管的生长。通过选择不同的沉积基底 
(石英或者二氧化硅基底), 可以实现碳纳米管水平 阵列或者薄膜的选择性制备, 说明了碳化钛固体 催化剂的形成优先碳纳米管生长, 验证了碳化钛 固体催化剂是碳纳米管生长的直接模板。

相比于其它碳化物固体催化剂的制备方法, 碳 化物催化剂浮动制备新方法具有以下优势：1)原 位获得的碳化物催化剂具有相当高的熔点, 保证 了催化剂在碳纳米管生长中的固体模板作用；2) 碳化物催化剂尺寸可以通过浮动载入量进行调 节，为制备不同直径或手性的碳纳米管奠定了基 础; 3)能够通过不同前驱体的选择, 实现不同种类 固体碳化物催化剂的制备, 甚至对固体碳化物催 化剂的结构进行调控; 4)能够排除生长过程中基 底对碳纳米管的影响, 揭示出固体催化剂与碳纳 米管之间更直接的相互作用。此外, 浮动制备法不 仅保证了大量固体催化剂的直接获得, 还可以确 保碳纳米管生长过程中, 固体催化剂的连续供给, 展示出应用于结构可控碳纳米管的宏量制备中的 巨大潜力。

上述研究工作近期在 Angewandte Chemie International Edition 上在线发表 9 。此项工作不仅 建立了碳化物固体催化剂的浮动制备方法, 进一 步证实了固体催化剂对碳纳米管结构的有效控 制, 而且为宏量制备结构单一的单壁碳纳米管提 供了新的思路。

\section{References}

(1) Zhang, R.; Zhang, Y.; Wei, F. Chem. Soc. Rev. 2017, 46, 3661. doi: 10.1039/C7CS00104E

(2) Yang, F.; Wang, X.; Zhang, D.; Yang, J.; Luo, D.; Xu, Z.; Wei, J.; Wang, J. -Q.; Xu, Z.; Peng, F.; et al. Nature 2014, 510, 522. doi: $10.1038 /$ nature 13434

(3) Zhang, S.; Kang, L.; Wang, X.; Tong, L.; Yang, L.; Wang, Z.; Qi, K.; Deng, S.; Li, Q.; Bai, X.; et al. Nature 2017, 543, 234. doi: $10.1038 /$ nature 21051

(4) Zhang, S.; Tong, L.; Zhang, J. Nat. Sci. Rev. 2018, 5, 310. doi: 10.1093/nsr/nwx080

(5) Zhang, S.; Wang, X.; Yao, F.; He, M.; Lin, D.; Ma, H.; Sun, Y.; Zhao, Q.; Liu, K.; Ding, F.; Zhang, J. Chem 2019, 5, 1182. doi: 10.1016/j.chempr.2019.02.012

(6) He, M.; Wang, X.; Zhang, S.; Jiang, H.; Cavalca, F.; Cui, H.; Wagner, J. B.; Hansen, T. W.; Kauppinen, E.; Zhang, J.; Ding, F. Sci. Adv. 2019, 5, eaav9668. doi: 10.1126/sciadv.aav9668

(7) Zhang, S.; Lin, D.; Liu, W.; Yu, Y.; Zhang, J. Small 2019, 15, 1903896. doi: 10.1002/smll.201903896

(8) Liao, Y.; Jiang, H.; Wei, N.; Laiho, P.; Zhang, Q.; Khan, S. A.; Kauppinen, E. I. J. Am. Chem. Soc. 2018, 140, 9797. doi: $10.1021 /$ jacs.8b05151

(9) Qian, L.; Xie, Y.; Yu, Y.; Wang, S.; Zhang, S. ; Zhang, J. Angew. Chem. Int. Ed. 2020. doi: 10.1002/anie.202002651 